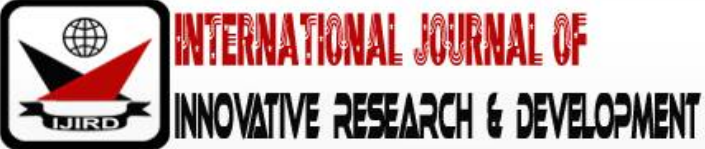

ISSN 2278 - 0211 (Online)

\section{Behavioural Reaction to Social Marketing Intervention against Non-Communicable Diseases: The Perception of Youth in Dungu, Ghana}

\author{
Gifty Obeng-Mensah \\ Student, Department of Nursing, UDS, Tamale, Ghana \\ Michael Wombeogo \\ Senior Lecturer, Department of Nursing, UDS, Tamale, Ghana \\ David Kanligi \\ Student, Department of Nursing, UDS, Tamale, Ghana \\ Rita Baidoo \\ Student, Department of Nursing, UDS, Tamale, Ghana
}

\begin{abstract}
:
This study assesses the perceived behavioural reaction of the youth of Dungu towards social marketing intervention against non-communicable diseases (NCDs).The method employed was based on the theory of reasoned action, a social marketing interventions approach involving the use of commercial marketing principles to influence the behaviour of the youth against harmful lifestyle. The results revealed that all respondents had heard about NCDs. Majority (82.4\%) of respondents perceived lifestyle modification was possible with social marketing interventions. In rating the understanding of the message,76.6\% said the information was well communicated, $23.4 \%$ said not well communicated and $28.5 \%$ of respondents said the information they received was scary. However $15 \%$ of the respondents stated they would not change. The authors recommend that social marketing should be tailored more towards the youth against perceived lifestyles risk factors that have a potential of increasing risk of NCDs in Ghana in general.
\end{abstract}

Keywords: Social Marketing, Social marketing intervention, Behaviour, Non-communicable disease, Dungu

\section{Introduction}

Non communicable diseases are diseases of lifestyle and are of long duration and generally slow in progression. The four main NCD types are cardiovascular disease (heart attacks and stroke), cancer, chronic respiratory diseases (such as chronic obstructed pulmonary disease and asthma) and diabetes. Andreasen (2012), stated that non-communicable disease is a global burden of the $21^{\text {st }}$ century which causes $86 \%$ of all deaths in the European Union (EU) and $65 \%$ of deaths worldwide, a third of these deaths occur before the age of sixty years. Dalal et al. (2011) reported a projection of NCDs to become the commonest cause of death by the year 2030. In a similar vein, Nikolic (2011) puts NCD deaths in Africa among persons aged 15-59 years to increase from 28\% to $41 \%$ between 2008 and 2030. A study conducted in Ghana by Nelson et al. (2015) indicates a relationship of a number of risk factors for NCDs such as, tobacco use, alcohol consumption, overweight, bad eating habits and physical inactivity to attitudes of people. Hence, behaviour is the commonest presage for the development of non-communicable diseases. AccordinglyMathur (2011), posits thatknowledge, attitudes and behaviors in relation to healthy eating, physical activity and healthy weight are vital to NCDs prevention. The main aim of social marketing is to exchange an undesirable behavior with a desirable one, and is considered a success when both the social marketer and the clients are satisfied with the exchange (Brisibe, Ordinioha \& Gbeneol, 2015). It involves the use of commercial marketing strategies in public education and awareness creation towards achieving lifestyle modification for the prevention of NCDs, thus creating a healthy society (Andreasen, 2006). In social marketing, understanding human behaviour is a crucial aspect of achieving campaign effectiveness. As a result, social marketing interventions are shaped by various behavioural theories, including diffusion of innovation, social cognitive, stages of change, health belief model and theory of reasoned action (Brisibe, Ordinioha \& Gbeneol, 2015; Lefebvre, 2000).

\section{Literature Review}

Behaviour is a complex human mechanism of coping and to change it a basic understanding is of its key determinants are required. How people behave is determined by many factors and is deeply embedded in social situations, institutional contexts and cultural norms (Australian Public Service Commission, 2007). Social marketing Interventions 
are aimed primarily at influencing behavioural change. However, people go through series of stages in the change process. Understanding the effect of change on people's identity is crucial to help centralize gains with social marketing interventions which aim at long term behavioural maintenance.

To really engage someone you need to know what matters to each individual, what's going on under the surface especially if you need to find ways of encouraging them to focus on possibilities rather than what the change is likely to costs them (Gateshead council, 2009) . This is why social marketers call for target segmentation and research (Adreasen, 2002) as people respond to changes in very different ways. The diagram below throws more lights on people response to change messages.

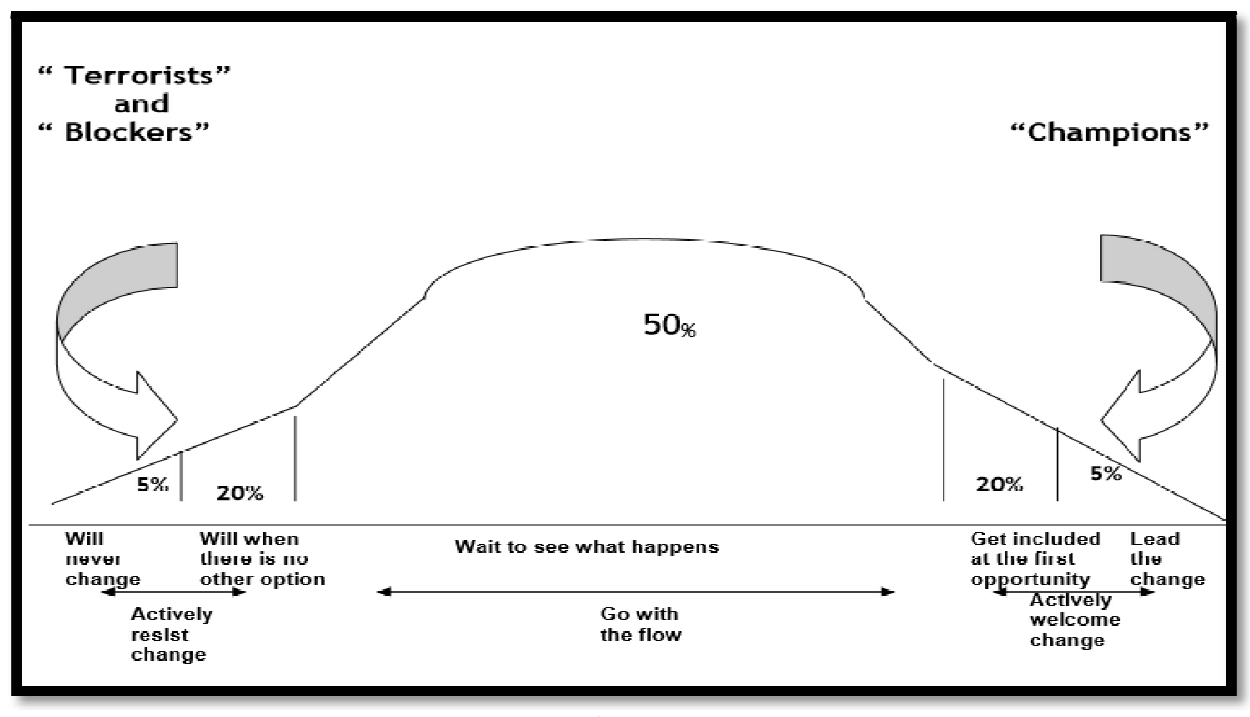

Figure 1

\subsection{Reactions to Change: Adapted from Gates Head Council, 2009}

The enthusiasts, see it as an opportunity, get a buzz from the challenge and a new sense of direction, and champion the change. Some people are a bit more cautious- they sit back and wait to see what happens. Others too see it as a threat may withdraw or resist until there is no other option. There are the cynics- the "yes butters"..."yes but that will never work"..."we tried that before". Others (the terrorists) might block or even sabotage the change process. There are usually a small number who have learned to live through change programmes without really changing at all (Gateshead Council, 2009).

In this regard, $5 \%$ of people will lead the change, $20 \%$ get involved at the first opportunity, $50 \%$ wait and see what happens. 20\% will change when there is no other option, but $5 \%$ will never change at all (Gateshead Council, 2009). It is imperative therefore that social marketing employs this ideology of differences in reaction to the 'threats' of lifestyle modification, puts measures to address them, and most importantly, follows up with repeated interventions that will help break the 'ices' and sustain progress (Farrelly, Niederdeppe \& Yarsevich, 2003). This is even more adaptable to the youth who fish around for identify and strive to mold their character; sometimes becoming antagonistic to the norms and values of society. Introducing interventions that appeal to their unstable mindsets could in diverse ways crown in the assimilation of enduring behavioural patterns. Understanding the reactions of targets to changes is therefore crucial for interventions aiming to modify youth physical activity level, diet, alcohol and smoking habits.

\section{Methodology}

\subsection{The Setting}

The study was conducted in Dungu; a peri-urban community in the Tamale Metropolis located 5km from the centre of Tamale Township to the right side of the main Tamale-Kumasi Road. Dungu community has a total population of 2623 people. Out of the total population, 1402 are males and 1221 females of which the majority are Dagomba and minorities are Frafra, Dagaaba, Gonja, Asante and others. The community has a total number of 496 households and 262 houses (GSS, 2010).

The Tamale Metropolis is one of the districts in the Northern Region. It is located in the central part of the Region and shares boundaries with the Sagnarigu District to the west and north, Mion District to the east, East Gonja to the south and Central Gonja to the south-west (now part of the Savannah Region of Ghana). The Metropolis has a total estimated land size of 646, 918sq. km (GSS, 2010).Geographically, the Metropolis lies between latitude 9o16 and 9o 34 north and longitudes 0 o 36 and 0 - 57 west. From the 2010 Population and Housing Census, the population of the Tamale Metropolis is 223,252 . The number of males stands at 111,109 (49.7\%) and that of females is $112,143(50.2 \%)$. The Metropolis has a total estimated land size of 646.90180 sq. km (GSS, 2010). The study population consists of youth within the age range of 15-24, who are resident in Dungu community. 


\subsection{The Study Design}

The study conducted was pure or basic in nature because the information gathered is a contribution to already existing information and is based on the theory of reason action (Brisibe, Ordinioha \& Gbeneol, 2015). It was a descriptive study as it sought to throw more light on the contribution of social marketing in combating the non-communicable disease menace in Dungu, Tamale, Ghana. Kothari (2004) indicates that the major purpose of descriptive research is description of the state of affairs as it exists at the present.

\subsection{Sampling Techniques}

A convenient sampling technique was used to select the study area or setting. Dungu community was selected for the study as a result of cost effectiveness and the diversity of ethnic groups present there. Simple random sampling was used in recruiting the respondents. Individuals whose ages fell within the age range for our study were selected for the study. A semi-structured questionnaire consisting of open and close ended questions was used in gathering the data. A total of 277 respondents in the community were recruited using simple random sampling. The questionnaires were entered into a pre-coded SPSS version 21 for analysis. The results were then presented in the form of tables and graphs for easy description and interpretations as indicated in the ensuing paragraphs.

\section{Differences in Behaviour towards the Information Received on NCD Prevention}

\subsection{Results/ Findings}

The results also indicate that the respondents had different opinions regarding information they had received on NCDs prevention. Majority of the respondents (76.6\%) accepted that the information was well communicated to them. Whilst $49(17 \%)$ of respondents said the message was not well communicated, a few of the respondents (15) asserted that they did not understand the language that was used to convey the message. The results are tabulated below.

\begin{tabular}{|c|c|c|c|}
\hline & Frequency & Percent & Cumulative Percent \\
\hline Well communicated & 209 & 76.6 & 76.6 \\
\hline Not clear & 49 & 17.9 & 94.5 \\
\hline Did not understand the language & 15 & 5.5 & 100.0 \\
\hline Total & 273 & 100.0 & \\
\hline
\end{tabular}

Table 1: Respondents Perception about Messages They Receive on NCDS

\subsection{Respondents Reactions to Messages}

Since the respondents had varied opinions, they also reacted differently to the information they had received on non-communicable diseases prevention. $105(38.5 \%)$ of them said the information they received scared them from engaging in certain lifestyles such as eating fatty foods, drinking alcohol, etc. A further $35 \%$ (97 respondents) said the messages motivated them to change their lifestyles, whilst 7.3\% said the message did not motivate in any way. However 43(15.8\%) of the respondents confirmed from the survey that though they were scared, the information they had received on non-communicable diseases motivated them to change as well. 8 of the respondents were of different opinions regarding their reactions to the information on NCDs.

\begin{tabular}{|ll|c|c|}
\hline \multicolumn{2}{|c|}{ Reaction to Message } & Frequency & Percent (\%) \\
\hline 1. & The message made me afraid & 105 & 38.5 \\
\hline 2. & Motivated me to change & 97 & 35.5 \\
\hline 3. & Did not motivate me & 20 & 7.3 \\
\hline 4. & Both scared and motivated to change & 43 & 15.8 \\
\hline $5 . \quad$ Others & 8 & 2.9 \\
\hline \multicolumn{2}{r|}{ Total } & 273 & 100.0 \\
\hline
\end{tabular}

Table 2: Respondents Reactions to Preventive Messages

\subsection{Respondent's Perceptions about Environmental Influences to Change}

Individuals as well as societal attitudes and behaviours are shaped by factors that revolve around them. The respondents thus enumerated some of the factors that they perceive to have influenced their behaviour and could affect the uptake of campaign messages. Most of the respondents (86 representing 31.5\%) revealed that message uptake could be enhanced if incorporated into their religious beliefs. 34 (12.5\%) of the respondents believed that peer influence could affect them, whilst 30 (11.0\%) said family is the dominant factor that influence campaign effectiveness. Though 24 (8.8\%) of respondents opted for interpersonal message delivery interventions and 27 (9.9\%) responded to all options, 61 $(22.3 \%)$ of the respondents felt that the way the message came was fine with them. However, a small fraction of the respondents (4.0\%) indicated that family and religion should be involved to potentiate effectiveness of campaigns. 


\section{Discussion}

The research assesses the respondents' views about the information they had received on NCDs prevention and their reaction to it. The results indicate that the respondents had different views regarding the information they had received. Rating the understanding of the messages, more than half of the respondents $(76.6 \%)$ accepted that the information was well communicated to them whilst $23.4 \%$ said the message was not well communicated. This implies that the respondents were bound to react differently to preventive campaigns as perception has strong influence on behaviour.

Thus recalling from their past exposure to such messages, $28.5 \%$ of the respondents inferred that the information they received scared them from the mere thoughts of engaging in certain lifestyles such as eating fatty foods, drinking alcohol, among others. This correlates with the Health Believe Model explained by Lefebvre (2000) where he stated that issues of fear- or anxiety-arousing messages often take place within the context of increasing perceived threat. Thus, a few of the youth of Dungu may react to messages that present threatening themes by adopting healthier lifestyles (such as engaging in regular active exercises, eating healthy foods and avoiding cigarette and alcohol) that guards them against developing NCDs in adulthood. A further 35\% of the respondents said the messages motivated them to change their lifestyles. This finding is also consistent with a study conducted by the Australian Service Commission (2007), which asserted that people assess health choices before them in terms of costs and benefits and then select the choice that maximises their net benefits. This underlies the rational choice model (Prager, 2012) which assumes people rationally seek to maximise their welfare. If people know that some behaviour and/ or activity have adverse effect; they will reduce its occurrence, thereby leading to lifestyle modification that will prevent the development of non-communicable diseases. This brings theory into play with interventions by applying models to enhance behaviour change; thus what social marketing seeks to accomplish. The findings also reveal that $7.3 \%$ of respondents said the message did not motivate them in any way. These can be compared to the 'cynics' in the report by Gateshead Council (2009) representing a small fraction of population who live through change programmes without really changing at all. It is paramount to note that though in the minority, such groups can serve a big blow to campaign effectiveness as they tend to counteract the interventions.

Though there are variations within the findings, holistically the results agree to the reports of Gateshead (2009) and the Australian Service Commission (2007) who proposed that change is not evenly distributed among populations and behaviour change can occur at the individual, interpersonal and community levels respectively.

\section{Recommendations and Conclusion}

\subsection{Conclusion}

In conclusion, the result revealed that though social marketing interventions have succeeded in creating awareness on contributory factors of NCDs, it is not enough to motivate people to change. This is attested by 41 (15\%) of the respondents saying that they would not change even if they were aware that certain lifestyle patterns were detrimental to their health. When the 41 respondents were asked why they intended not to change irrespective of the awareness of these detrimental lifestyle patterns, 11 of them believed they were not at risk of NCDs, 9 of them said the message they heard about NCDs was not convincing enough to make them change. 4 of the respondents admitted they lacked the self-will to change, while 17 of them said they would feel uncomfortable among their peers if they decide to change.

The study also brought to light the fact that one cannot overlook the core role the environment (physical and social) of an individual plays in the behavioral change process. When the respondents were asked which factors can best improve the uptake of health campaign messages, $31.5 \%$ chose religion, $12.5 \%$ selected peer influence, $11.0 \%$ selected family whilst $8.8 \%$ of respondents resolved for interpersonal message delivery.

\subsection{Recommendations}

- The implementers of social marketing interventions such as the Ghana Social Marketing foundation should target different segments (adults, youth, and children) of the Ghanaian population with tailor-made interventions in order to facilitate uptake.

- The Ghanaian food and drugs authority should regulate media (radio and TV specifically) advertisement concerning alcoholic beverages since they serve as detractors to behavior change interventions

\section{Acknowledgements}

The authors are grateful to all opinion leaders and the youth of Dungu who gave the researchers the permission to and participated in the interview as respondents for this study. We are also grateful to all who supported the study and offered various helpful advice and inputs during the data gathering phase of the study

\section{References}

i. Andreasen, A.R. (2002) Marketing social marketing in the social change market place. Journal of Public Policy and Marketing.Vol 21 No 1, pp3-13.

ii. Andreasen, A.R.(2006). Social Marketing in the 21st century. Thousand Oak. CA: Sage Publications.

iii. Australian Public Service Commission (2007).Changing Behaviour: a public Policy Perspective. Australia: Commonwealth of Australia

iv. Brisibe, S.F., Ordinioha B. \& Gbeneol, P (2015). "Framework for the social marketing of clinical preventive services in nigeria." World Journal of Preventive Medicine, vol. 3, no.1. 
v. Dalal, S. Beunza, J.J, Volmink. et al (2011). Non-communicable diseases in sub-saharan Africa: What we know now. Int J Epidemiol, 40:885-901.

vi. Farrelly, M.C, Niederdeppe, J\&Yarsevich, J (2003). Youth tobacco prevention mass media campaign:past, present and future directions. Tobacco Control. doi:10.1136/tc.12.suppl_1.i35-i47.

vii. Gateshead Council (2009), Understanding\& Managing Reactions to Change. http:/ / www.gateshead.gov.uk

viii. Ghana Statistical Service (2014). District Analytical Report: Tamale Metropolis, Accra: GSS

ix. Kothari, C. R (2004). Research methodology: methods and techniques $2^{\text {nd }}$ ed. New Delhi: New age international publishers

x. Lefebvre, RC (2000). In PN Bloom \& GT Gundlach (Eds.), Handbook of Marketing and Society, Newbury Park, CA: Sage Publications

xi. Mathur, A. (2011). Youth knowledge and practices towards noncommunicable d Disease Risk Factors in Pohnpei, Federated States of Micronesia. Global Health: Pohnpei.

xii. Nikolic, I.A, Stanciole, A.E\& Zaydman M. (2011). Chronic emergency: why ncds matter. Washington, DC: World Bank. 